\title{
La práctica de la Cardiología ante la pandemia por COVID-19. Recomendaciones de la comunidad cardiológica mexicana
}

\section{Practice of Cardiology during COVID 19 pandemic. Recommendations of the Mexican Cardiology Community}

\author{
Carlos R.Sierra-Fernández ${ }^{*}$, Marco A. Alcocer-Gamba² y Alfonso Buendía-Hernández ${ }^{3}$ \\ ${ }^{1}$ Director de Enseñanza del Instituto Nacional de Cardiología Ignacio Chávez; ${ }^{2}$ Presidente de la Sociedad Mexicana de Cardiología; ${ }^{3}$ Editor en \\ Jefe. Comité Editorial de Archivos de Cardiología de México, Ciudad de México
}

En diciembre de 2019 los servicios de salud de la ciudad de Wuhan en China comenzaron a percatarse de un aumento, fuera de lo habitual, en la incidencia de cuadros infecciosos respiratorios graves. Se trataba de una serie de casos de neumonía de focos múltiples de progresión rápida y pronóstico desfavorable. Los sistemas de vigilancia epidemiológica local, que han sido particularmente activos desde la epidemia de SARS en 2002, trabajaron arduamente en analizar los casos y establecer las características del brote. En poco menos de un mes se había identificado que este cuadro clínico corresponde a una infección viral, cuyo agente es un nuevo miembro de la familia coronaviridae, especificamente un tipo de beta coronavirus, cuya semeajanza genotípica con SARS es muy alta, siendo prácticamente idéntico a formas virales causales de enfermedad en murciélagos lo que apoya a la transmisión zoonotica de un virus que por evolución filogenética adquirió la habilidad de infectar al humano y transmitirse de persona a persona a través de gotas ${ }^{1}$.

Para incios del año 2020 los científicos chinos habían secuenciado la totalidad el genoma viral, nombrándole inicialmente novel coronavirus 2019 (2019 $\mathrm{nCoV}$ ) y posteriromente se presentó a la comunidad científica internacional como SARS CoV-2, virus causal de la enfermedad COVID-19. La rápida dispersión del germen por otras regiones de Asia, Europa y norte de
América, causando un elevado número de casos graves y contagios totales, motivó a la Organización Mundial de la Salud a denominarla pandemia el 11 de marzo de 2020. La dispersión ha alcanzado todas las regiones del mundo y los casos confirmados superan en este momento los tres millones².

Nunca en tan poco tiempo se ha conocido tanto sobre una enfermedad, como ahora se concoce sobre COVID-19. Los grupos científicos más destacados a nivel mundial han puesto en pausa sus líneas de investigación para concentrar esfuerzos en torno a COVID. Así mismo lo han hecho los investigadores clínicos y los centros sanitarios académicos, quienes han aportado gran cantidad de reportes, recomendaciones, observaciones y datos sobre el curso de la enfermedad.

En este mar de datos e información es crucial que las agrupaciones científicas se den a la tarea de clasificar, organizar, ponderar y resumir la evidencia disponible para emitir recomendaciones prácticas para el clínico en la primera línea de contacto con la enfermedad. Hoy más que nunca es necesario mantener el rigor científico, distinguir la evidencia de la anécdota, la hipótesis del dato objetivo y la experiencia individual del comportamiento universal.

En este sentido, Archivos de Cardiología de México en conjunto con el Instituto Nacional de Cardiología y la Sociedad Mexicana de Cardiología hemos invitado a

\section{Correspondencia:}

${ }^{*}$ Carlos R. Sierra-Fernandez

E-mail: drsierra@ cardios.mx
Disponible en internet: 26-05-2020 Arch Cardiol Mex. 2020;90(Supl):5-6 www.archivoscardiologia.com 1405-9940 / @ 2020 Instituto Nacional de Cardiología Ignacio Chávez. Publicado por Permanyer. Este es un artículo open access bajo la licencia CC BY-NC-ND (http://creativecommons.org/licenses/by-nc-nd/4.0/). 
un grupo multidisciplinario de expertos en Cardiología y áreas afines para que en función de la evidencia disponible al momento se emitan comunicaciones científicas breves que den luz y certidumbre al profesional de la medicina cardiovascular. El suplemento extraordinario de nuestra revista toca aspectos relevantes del COVID-19 y la cardiología, desde un enfoque plural, abierto, multidisciplinario y plurigeneracional. Se incluye en este suplemento el documento de postura que encabezan la Asociación Nacional de Cardiólogos de México y la Sociedad Mexicana de Cardiología sobre las recomendaciones para la práctica clínica en Cardiología en relación con la pandemia COVID-19. Texto fundamental de consulta y referencia para la toma de decisiones informadas en el contexto clínico, con evidencia científica y recomendaciones prácticas en donde se aplican y adaptan los escenarios a la realidad nacional.
Esta pandemia es el reto profesional más importante para los médicos de esta generación, los elementos para enfrentarlos son el conocimiento, la práctica basada en evidencias, la empatía y el humanismo. Sirva este esfuerzo para ofrecer luz al clínico que está en la primera línea de combate, que reciba de este texto los elementos necesarios para su actuar profesional y que las futuras generaciones encuentren en este ejemplo de cooperación científica abierta y transversal la inspiración para construir una sociedad del conocimiento libre, abierto y colaborativo.

\section{Bibliografía}

1. Li Q, Guan X, Wu P, Wang X, Zhou L, Med M. et al. Early Transmission Dynamics in Wuhan, China of Novel Coronavirus-Infected Pneumonia. N Eng J Med 2020; 382(13).

2. Omer S, Malani P y Del Rio C. JAMA 2020; DOI:10.1001/jama.2020.5788. 